\title{
Human papillomavirus antibody response following HAART initiation among MSM
}

\author{
Jean-Damien Combes ${ }^{a}$, Gary M. Clifford ${ }^{a}$, Matthias Egger ${ }^{b}$, \\ Matthias Cavassinic, Hans H. Hirsch ${ }^{\mathrm{d}}$, Christoph Hauser ${ }^{\mathrm{e}}$, \\ Alexandra Calmy ${ }^{\mathrm{f}}$, Patrick Schmid ${ }^{\mathrm{g}}$, Enos Bernasconi ${ }^{\mathrm{h}}$, \\ Huldrych F. Günthard ${ }^{\mathrm{i}, \mathrm{j}}$, Silvia Franceschi ${ }^{\mathrm{a}}$, Tim Waterboer ${ }^{\mathrm{k}}$, \\ Alexandra U. Scherrer ${ }^{\mathrm{i}, \mathrm{j}}$, the Swiss HIV Cohort Study
}

Objective: To describe effects of HAART on high-risk human papillomavirus (HPV) antibody response in HIV-positive MSM and the meaning of this response for subsequent HPV-related cancer risk.

Design: Prospective seroepidemiological study of 281 HIV-positive MSM initiating HAART between 1995 and 2004 in the Swiss HIV Cohort Study.

Methods: For each individual, two serum samples, one at HAART initiation (pre-HAART) and another 24 months later (post-HAART), were tested for L1 antibodies to HPV6, 11, 16, 18, 31, 33, 35, 45, 52 and 58, as well as HPV16-E6 antibodies, using a multiplex serology assay. Identification of HPV-related cancer included data linkage with Swiss cancer registries.

Results: Pre-HAART, 45.2\% were seropositive for any high-risk HPV-L1 and 32.4\% for HPV16-L1. Sexual intercourse during the last 6 months was the only evaluated factor associated with L1 seropositivity pre-HAART. Seropositivity increased post-HAART to $60.5 \%$ for any high-risk HPV-L1 [prevalence ratio versus pre-HAART $=1.34$, 95\% confidence interval $(\mathrm{Cl})$ 1.14-1.57] and $48.0 \%$ for HPV16-L1 (prevalence ratio versus pre-HAART $=1.48,95 \% \mathrm{Cl} 1.20-1.83$ ), and seroconversion was significantly associated with both lower $\mathrm{CD} 4^{+}$cell count and $\mathrm{CD} 4^{+} / \mathrm{CD}^{+}$ratio $(P<0.01)$. Only one individual was HPV16-E6-seropositive pre-HAART, but two more seroconverted post-HAART. Anal cancer incidence among the three HPV16-E6-positives post-HAART was significantly increased compared with HPV16-E6-negatives (incidence rate ratio $=63.1,95 \% \mathrm{Cl} 1.1-1211)$.

Conclusion: HAART-related immune reconstitution increases HPV-specific antibody responses, which may discriminate future anal cancer risk in this high-risk population.

Copyright $\odot 2017$ Wolters Kluwer Health, Inc. All rights reserved.

AIDS 2017, 31:561-569

Keywords: anal cancer, HAART, HIV, human papillomavirus, serology

\footnotetext{
${ }^{\mathrm{a}}$ International Agency for Research on Cancer, Lyon, France, ${ }^{\mathrm{b}}$ Institute of Social and Preventive Medicine, University of Bern, Bern, ${ }^{\mathrm{C}}$ Division of Infectious Diseases, University Hospital Lausanne, Lausanne, ${ }^{\mathrm{d}}$ Division of Infectious Diseases and Hospital Epidemiology, University Hospital Basel, Basel, 'Department of Infectious Diseases, Bern University Hospital, University of Bern, Bern, ${ }^{f}$ HIV/AIDS Unit, Infectious Disease Service, Geneva University Hospital, Geneva, 'Division of Infectious Diseases, Cantonal Hospital St. Gallen, St. Gallen, hDivision of Infectious Diseases, Regional Hospital Lugano, Lugano, 'Division of Infectious Diseases and Hospital Epidemiology, University Hospital Zurich, University of Zurich, J Institute of Medical Virology, University of Zurich, Zurich, Switzerland, and ' Infection and Cancer Program, German Cancer Research Center, Heidelberg, Germany. Correspondence to Gary M. Clifford, International Agency for Research on Cancer, 150 Cours Albert Thomas, 69372 Lyon Cedex 08, France.
}

Tel: +33 472738425; fax: +33 472738345; e-mail: clifford@iarc.fr

Received: 29 September 2016; revised: 8 November 2016; accepted: 14 November 2016. 


\section{Introduction}

HIV-positive MSM have a high burden of anal high-risk human papillomavirus (HPV) infection [1]. Consequently, they also suffer a high incidence of anal cancer [1], for which persistent anal high-risk HPV infection, predominantly HPV16 [2], is the major cause. In the era of prolonged survival due to HAART, anal cancer incidence in HIV-positive MSM has reached more than 100 cases per 100000 person-years [3,4].

Antibodies to high-risk HPV L1 protein are considered as markers of cumulative HPV exposure. However, L1 seroconversion does not always occur following natural $\mathrm{HPV}$ infection, and seroconversion rates in men may differ by the anatomical site of HPV infection $[5,6]$. There have been relatively few studies that have evaluated HPV L1 seropositivity in HIV-positive MSM [6-9], and the association between anal high-risk HPV infection and the detection of HPV-L1 antibodies is not clear in this population [6].

Antibodies against HPV E6 protein, on the other hand, have been shown to be highly specific markers for HPVrelated cancer [10-16]. However, although HPV16-E6 is a highly sensitive marker for oropharyngeal cancer and can be consistently detected many years before cancer diagnosis $[14,16]$, the picture is less clear for anal and cervical cancer $[11,13,15]$ and even less so in HIV-positive persons $[10,12]$.

To our knowledge, there are no studies evaluating the specific effects of HAART immune reconstitution on HPV antibody responses, nor the meaning of these responses for long-term HPV-related cancer risk, which is important to prevent in this high-risk population. Hence, this study used a multiplex HPV serology method based on a glutathione $S$-transferase (GST) capture immunosorbent assay [17] to describe HPV-L1 and HPVE6 antibodies pre and post-HAART among a large sample of HIV-positive MSM [18], who were also followed up for cancer [3], within the framework of the Swiss HIV Cohort Study (SHCS).

\section{Methods}

Patients were participants in the SHCS, an ongoing study that has been enrolling persons infected with HIV since 1988 from five large university hospitals, two large cantonal hospitals, affiliated regional hospitals and private practitioners in Switzerland (www.shcs.ch). Detailed information on disease, laboratory tests and HIV-related treatments were collected at enrolment and at each 6-month follow-up visit [19].

A total of 1624 MSM initiated HAART between November 1995 and June 2004 while under active follow-up in the SHCS. We excluded 878 patients with prior use of any antiretroviral therapy. From this group, we identified 281 MSM who had serum samples available within 1 month before (pre-HAART) and 21-27 months after (post-HAART) HAART initiation [18].

Markers of immunodeficiency $\left(\mathrm{CD}^{+}{ }^{+}\right.$and $\mathrm{CD}^{+}$cell counts, $\mathrm{CD} 4^{+} / \mathrm{CD}^{+}$ratio, HIV viral load), AIDS status and tobacco consumption were extracted from the SHCS database. Questions on sexual intercourse during the last 6 months were asked at follow-up visits after April 2000 only. Individuals diagnosed with HPV-related cancer cases from HAART initiation until May 2016 were identified in the SHCS database and/or through record linkage with eight Swiss cancer registries $[3,20]$.

Antibodies were tested at the German Cancer Research Center, Heidelberg, Germany, using a multiplex HPV serology assay based on a GST capture ELISA [21,22] combined with fluorescence-labeled polystyrene beads (SeroMAP Microspheres; Luminex Corp., Austin, Texas, USA) [17,23]. Viral antigens were expressed in Escherichia coli as double fusion proteins with N-terminal GST and a C-terminal peptide (tag) derived from the large T-antigen of simian virus 40. Glutathione-casein was coupled to internally fluorescence-labeled polystyrene beads, and GST-fusion proteins were affinity purified on the beads directly in a one-step in-situ procedure. The differently labeled beads carrying different antigens were then mixed and incubated with human serum that had been diluted $1: 100$ in blocking buffer. Antibodies bound to the beads were then stained with biotinylated antihuman immunoglobulin followed by the fluorescent reporter conjugate streptavidin-R-phycoerythrin. A Luminex analyzer was used to quantify the antibodies bound to antigens on beads and to identify the antigen by bead color. Antibody quantity was determined as the median R-phycoerythrin fluorescence intensity (MFI) from at least 100 beads of the same internal color.

MFI values were dichotomized as antibody positive or negative. Cutoff values for HPV16, 18, 31, 33, 35, 45, 53 and $58 \mathrm{~L} 1$ were predetermined independently for each antibody by analyzing MFI values obtained from Korean HPV-DNA-negative virgin women using the algorithm of five SDs after exclusion of outliers [24]. Cutoff MFI values were defined at 1000 for HPV16-E6 [16,25], and 800 and 400 for HPV6 and HPV11 L1 [26]. For any highrisk HPV-L1, seropositivity was defined as positive for at least one HPV type among HPV16, 18, 31, 33, 35, 45, 53 and 58 .

Seroprevalence of HPV antibodies was calculated for strata of age, HIV viral load, $\mathrm{CD}^{+}$and $\mathrm{CD} 8^{+}$cell counts, and $\mathrm{CD} 4^{+} / \mathrm{CD}^{+}$ratio at HAART initiation. Differences between strata were compared by $\chi^{2}$ test or Cochran-Armitage trend test. At 24-month follow-up, changes in seropositivity for HPV antibodies were 
evaluated by crude prevalence ratios and corresponding $95 \%$ confidence intervals (CIs).

Factors associated with seroconversion were investigated in patients seronegative at HAART initiation, by calculating crude odds ratio (OR) of seroconversion and corresponding 95\% CI according to baseline characteristics. For any high-risk HPV-L1, seronegativity at HAART initiation was defined as negative for at least one HPV type among HPV16, 18, 31, 33, 35, 45, 53 and 58.

Type-specific mean MFI values at HAART initiation and at 24-month follow-up were compared among all 281 MSM (irrespective of being seronegative/positive) using Wilcoxon signed-rank sum test and were additionally compared across strata of $\mathrm{CD}^{+}{ }^{+}$at HAART initiation.

For anal cancer incidence rate analyses according to postHAART serology result, calculation of person-years at risk began at the date of post-HAART serology and ended on the date of last SHCS follow-up, anal cancer or death, whichever was earliest. Incidence rate ratios and corresponding 95\% CI were calculated using exact estimates.

\section{Results}

\section{Patient characteristics}

Of the 281 included MSM, mean age was 40.8 years (range 19.6-73.4) and $56(19.9 \%)$ had history of AIDS at HAART initiation (Table 1). At HAART initiation, mean $\mathrm{CD}^{+}{ }^{+}$cell count was 240 cells/ $\mu$ l (median 194, range 2-1037) and mean viral load 390000 copies/ml (median 100000 , range $0-8750000$ ). Post-HAART, mean $\mathrm{CD}^{+}{ }^{+}$was 504 cells/ $\mu \mathrm{l}$ (median 444, range $28-$ 1829 ) and mean viral load 20000 copies/ml (median 0 , range $0-2300000)$. Table 1 also shows associations of selected characteristics with HPV16-L1 and high-risk HPV-L1 seropositivity pre-HAART, of which only sexual intercourse during the last 6 months was statistically significant $(P=0.01$ and 0.04 , respectively).

\section{Human papillomavirus antibody seropositivity at date of HAART initiation (pre-HAART)}

Pre-HAART, 91 (32.4\%) participants were HPV16-L1seropositive (Table 2). Seropositivity for other high-risk HPV types ranged from $7.8 \%$ (HPV58) to $17.8 \%$ (HPV31), and 127 (45.2\%) were positive for at least one high-risk HPV type among HPV16, 18, 31, 33, 35, 45, 52 and 58 (Table 2). Seropositivity of HPV6 and HPV11 L1 were 40.2 and $29.2 \%$, respectively (Table 2 ). Only one participant $(0.4 \%)$ was positive for HPV16-E6 antibody pre-HAART.

\section{HAART-related changes in human papillomavirus antibody seropositivity}

Post-HAART, seropositivity of all evaluated HPV antibodies increased (Table 2). A total of 135 (48.0\%) participants were HPV16-L1-seropositive, corresponding to a prevalence ratio of 1.48 (95\% CI 1.20-1.83) compared with pre-HAART. Post-HAART seropositivity for other high-risk HPV types ranged from 14.2\% (HPV58) to 34.5\% (HPV31), and 170 (60.5\%) were seropositive for at least one high-risk HPV type. Prevalence ratios for high-risk HPV-L1 seropositivity post-HAART versus pre-HAART ranged from 1.64 (1.17-2.29) for HPV35 to 2.17 (1.51-3.13) for HPV18. Seroprevalence was $53.0 \%$ for HPV6 [prevalence ratio $=1.32(1.10-1.58)$ ] and $45.6 \%$ for HPV11 [prevalence ratio $=1.32(1.10-1.58)]$.

The one HPV16-E6-seropositive patient pre-HAART remained seropositive post-HAART, and two more individuals seroconverted, resulting in a total of three seropositive (1.1\%) post-HAART [prevalence ratio $=3.00(0.31-28.7)]$.

Factors associated with seroconversion are described in Table 3. Among participants HPV16-seronegative preHAART, seroconversion for HPV16-L1 was associated with low $\mathrm{CD}^{+}$cell count $[\mathrm{OR}=5.28(1.88-14.8)$ for $\mathrm{CD}^{+}<50$ versus $\geq 350$ cells $\left./ \mu \mathrm{l}\right]$ and low $\mathrm{CD} 4^{+} / \mathrm{CD}^{+}$ ratio $\left[\mathrm{OR}=6.56(1.98-21.71)\right.$ for $\mathrm{CD}^{+} / \mathrm{CD}^{+}$ratio $<0.10$ versus $\geq 0.5$ ] at HAART initiation. Results were consistent for seroconversion for any high-risk HPV-L1 (Table 3) and were statistically significant for certain individual types: low $\mathrm{CD}^{+}$cell count with seroconversion of HPV31, 33 and 52 and low $\mathrm{CD}^{+} / \mathrm{CD}^{+}$ratio with seroconversion of HPV31, 33, 35, 45 and 52 (data not shown).

\section{Changes in human papillomavirus antibody titers}

Between pre-HAART and post-HAART, mean MFI values (a semiquantitative measure of antibody titers) increased for all evaluated HPV-L1 antibodies (Fig. 1a) and were statistically significant for all high-risk HPV types. Mean MFI values for HPV16-L1 increased from 600 to 950 , and increases were greatest for participants with $\mathrm{CD}^{+}{ }^{+}$cell count less than 50 cells/ $\mu$ l (Fig. 1b).

\section{Incidence of human papillomavirus-related cancer}

The 281 included MSM were actively followed up in the SHCS for a total of 3771 person-years following HAART initiation, including 558 person-years before and 3213 person-years after the date of post-HAART serology. Five incident anal (and no oropharyngeal or penile) cancers were diagnosed during this time, corresponding to an overall anal cancer incidence rate of 132/100 000 personyears, of which two were diagnosed before and two after the date of post-HAART serology.

Associations between HPV16 serology status postHAART (by which time many participants had seroconverted) and anal cancer incidence are shown in Table 4. Anal cancer incidence was $0 / 100000$ person- 
Table 1. Human papillomavirus antibody seropositivity among $281 \mathrm{MSM}$, overall and by selected characteristics, at HAART initiation.

\begin{tabular}{|c|c|c|c|c|c|}
\hline & \multirow[b]{2}{*}{$n$} & \multicolumn{2}{|c|}{ HPV16-L1 } & \multicolumn{2}{|c|}{ Any HR-HPV-L1 ${ }^{a}$} \\
\hline & & $n(\%)$ & $P^{\mathrm{b}}$ & $n(\%)$ & $P^{\mathrm{b}}$ \\
\hline \multicolumn{6}{|l|}{ Age (years) } \\
\hline$\geq 45$ & 81 & $28(34.6)$ & & $40(49.4)$ & \\
\hline $35-44$ & 104 & $38(36.5)$ & & $52(50.0)$ & \\
\hline$<35$ & 95 & $25(26.3)$ & 0.22 & $35(36.8)$ & 0.09 \\
\hline \multicolumn{6}{|l|}{ Tobacco } \\
\hline Ever & 159 & $46(28.9)$ & & 65 (40.9) & \\
\hline Never & 118 & $43(36.4)$ & 0.19 & $60(50.9)$ & 0.10 \\
\hline \multicolumn{6}{|l|}{ History of AIDS } \\
\hline Yes & 225 & $76(33.8)$ & & $104(46.2)$ & \\
\hline No & 56 & $15(26.8)$ & 0.32 & $23(41.1)$ & 0.49 \\
\hline \multicolumn{6}{|c|}{ Sexual intercourse in the last 6 months ${ }^{c}$} \\
\hline None & 21 & $5(23.8)$ & & $8(38.1)$ & \\
\hline Steady partner only & 20 & $5(25.0)$ & & $10(50.0)$ & \\
\hline Occasional partner(s) only & 21 & $9(42.9)$ & & $13(61.9)$ & \\
\hline Steady and occasional partner(s) & 14 & $9(64.3)$ & 0.01 & $10(71.4)$ & 0.04 \\
\hline \multicolumn{6}{|l|}{ HIV viral load (copies/ml) } \\
\hline$<10000$ & 38 & $13(34.2)$ & & $14(36.9)$ & \\
\hline $10000-99999$ & 99 & $28(28.3)$ & & $44(44.4)$ & \\
\hline $100000-499999$ & 90 & $29(32.2)$ & & $44(48.9)$ & \\
\hline$\geq 500000$ & 46 & $20(43.5)$ & 0.24 & $23(50.0)$ & 0.19 \\
\hline \multicolumn{6}{|l|}{$\mathrm{CD}^{+}$cell count $(\mathrm{cells} / \mu \mathrm{l})$} \\
\hline$\geq 350$ & 68 & $22(32.4)$ & & $27(39.7)$ & \\
\hline $200-350$ & 71 & $24(33.8)$ & & $34(47.9)$ & \\
\hline $50-199$ & 93 & $33(35.9)$ & & $48(51.6)$ & \\
\hline$<50$ & 49 & $12(24.5)$ & 0.55 & $18(36.7)$ & 0.87 \\
\hline \multicolumn{6}{|l|}{$\mathrm{CD8}^{+}$cell count $(\mathrm{cells} / \mu \mathrm{l})$} \\
\hline$\geq 1000$ & 89 & $35(39.3)$ & & 45 (50.6) & \\
\hline $750-999$ & 58 & $14(24.1)$ & & $18(31.0)$ & \\
\hline $500-749$ & 66 & $21(31.8)$ & & $34(51.5)$ & \\
\hline$<500$ & 68 & $21(30.9)$ & 0.35 & $30(44.1)$ & 0.83 \\
\hline \multicolumn{6}{|l|}{$\mathrm{CD}^{+} / \mathrm{CD}^{+}{ }^{\text {ratio }}$} \\
\hline$\geq 0.5$ & 47 & $13(27.7)$ & & $17(36.2)$ & \\
\hline $0.25-0.49$ & 80 & $28(35.0)$ & & $39(48.8)$ & \\
\hline $0.10-0.25$ & 89 & $34(38.2)$ & & $46(51.7)$ & \\
\hline$<0.10$ & 61 & $16(26.2)$ & 0.9 & $25(41.0)$ & 0.65 \\
\hline
\end{tabular}

HPV, human papillomavirus; HR, high risk; SHCS, Swiss HIV Cohort Study.

${ }^{a}$ Any HPV-L1: seropositivity of at least one HPV type among HPV16, 18, 31, 33, 35, 45, 52 and 58.

${ }^{\mathrm{b}}$ Cochran-Armitage trend test used for ordinal categories, $\chi^{2}$ test for dichotomous categories.

${ }^{\mathrm{c}}$ Asked to SHCS participants at follow-up visits after April 2000 only $(n=76)$.

years for post-HAART HPV16-L1 seronegatives versus 196/100 000 person-years for seropositives, corresponding to a nonsignificant incidence rate ratio of $\infty(95 \% \mathrm{CI}$ $0.5-\infty)$ and 63/100 000 person-years for HPV16-E6 seronegatives versus 3956/100000 person-years in seropositives, corresponding to a statistically significant incidence rate ratio of 63.1 (95\% CI 1.1-1211) (Table 4).

The participant who was HPV16-E6-seropositive both pre-HAART $\quad(\mathrm{MFI}=1408)$ and post-HAART $(M F I=1916)$ had not developed anal cancer by 2016 , 15 years after post-HAART serology date. Of the two participants that seroconverted for HPV16-E6 postHAART, one died 7 months later following a diagnosis of lymphoma (pre-HAART $\mathrm{MFI}=63$; post-HAART MFI $=10909)$, and the other developed anal cancer 9 years later (pre-HAART $\mathrm{MFI}=10$; post-HAART MFI $=2382$ ).

\section{Discussion}

In a cohort of HIV-infected MSM, we were able to describe, for the first time to our knowledge, that HAART is associated with seroconversion and increasing titers of HPV antibodies. In this high-risk population, for whom approximately half were already seropositive for at least one high-risk HPV type before HAART, another fifth seroconverted to high-risk HPV-L1 in the 2 years following HAART initiation. Those with the lowest $\mathrm{CD} 4^{+}$cell count and $\mathrm{CD} 4^{+} / \mathrm{CD}^{+}$ratio at HAART initiation were the most likely to seroconvert, suggesting that HAART-related immune reconstitution contributes to revealing a detectable immune response to HPV. This was apparent even for HPV16-E6 antibodies, for which two out of three seropositive cases were detected only post-HAART. Furthermore, although numbers of cancer cases were small, HAART-related seroconversion seemed 
Table 2. Changes in human papillomavirus antibody seropositivity at HAART initiation and 24-month follow-up in 281 MSM.

\begin{tabular}{|c|c|c|c|c|c|c|c|}
\hline & \multirow{2}{*}{$\begin{array}{c}\text { Pos at HAART } \\
\text { initiation } \\
n / \text { total }(\%)\end{array}$} & \multirow{2}{*}{$\begin{array}{l}\text { Pos at 24-month } \\
\text { follow-up } \\
\text { n/total }(\%)\end{array}$} & \multirow{2}{*}{$\begin{array}{c}\text { Prevalence ratio } \\
(95 \% \mathrm{Cl})\end{array}$} & \multicolumn{4}{|c|}{ Status at both time points } \\
\hline & & & & $+/+$ & $+1-$ & $-1+$ & $-1-$ \\
\hline HPV16-L1 & $91 / 281(32.4)$ & $135 / 281(48.0)$ & $1.48(1.20-1.83)$ & $80(28.5)$ & $11(3.9)$ & 55 (19.6) & $135(48.0)$ \\
\hline HPV18 L1 & $35 / 281(12.5)$ & $76 / 281(27.1)$ & $2.17(1.51-3.13)$ & $28(10.0)$ & $7(2.5)$ & $48(17.1)$ & $198(70.5)$ \\
\hline HPV31 L1 & $50 / 281(17.8)$ & $97 / 281(34.5)$ & $1.94(1.44-2.61)$ & $45(16.0)$ & $5(1.8)$ & $52(18.5)$ & $179(63.7)$ \\
\hline HPV33 L1 & $27 / 281(9.6)$ & $55 / 281(19.6)$ & $2.04(1.33-3.13)$ & $24(8.5)$ & $3(1.1)$ & $31(11.0)$ & $223(79.4)$ \\
\hline HPV35 L1 & 44/281 (15.7) & $72 / 281(25.6)$ & $1.64(1.17-2.29)$ & $41(14.6)$ & $3(1.1)$ & $31(11.0)$ & $206(73.3)$ \\
\hline HPV45 L1 & $31 / 281(11.0)$ & 83/281 (29.5) & $2.68(1.83-3.91)$ & $25(8.9)$ & $6(2.1)$ & $58(20.6)$ & $192(68.3)$ \\
\hline HPV52 L1 & $36 / 281(12.8)$ & 64/281 (22.8) & $1.78(1.22-2.58)$ & $31(11.0)$ & $5(1.8)$ & $33(11.7)$ & $212(75.4)$ \\
\hline HPV58 L1 & $22 / 281(7.8)$ & $40 / 28(14.2)$ & $1.82(1.11-2.98)$ & $19(6.8)$ & $3(1.1)$ & $21(7.5)$ & $238(84.7)$ \\
\hline Any HR-HPV-L1 ${ }^{\mathrm{a}}$ & $127 / 281$ & $170 / 281(60.5)$ & $1.34(1.14-1.57)$ & $116(41.3)$ & $11(3.9)$ & $54(19.2)$ & $100(35.6)$ \\
\hline HPV6 L1 & $113 / 281(40.2)$ & $149 / 281(53.0)$ & $1.32(1.10-1.58)$ & $96(34.2)$ & $17(6.1)$ & $53(18.9)$ & $115(40.9)$ \\
\hline HPV11 L1 & $82 / 281(29.2)$ & $128 / 281(45.6)$ & $1.56(1.25-1.95)$ & $73(26.0)$ & $9(3.2)$ & 55 (19.6) & $144(51.3)$ \\
\hline HPV16-E6 & 1/281 (0.4) & 3/281 (1.1) & $3.00(0.31-28.7)$ & $1(0.4)$ & $0(0.0)$ & $2(0.7)$ & $278(98.9)$ \\
\hline
\end{tabular}

$\mathrm{Cl}$, confidence interval; HPV, human papillomavirus.

${ }^{a}$ Any HPV-L1: seropositivity of at least one HPV type among HPV16, 18, 31, 33, 35, 45, 52 and 58.

to improve the ability of HPV16-L1 and E6 antibody status to discriminate future anal cancer risk.

Increases in seroprevalence and mean MFI values were observed for all eight evaluated high-risk HPV-L1 antibodies. Seroconversion rates were far above those of seroreversion and so could not be explained by random fluctuation of test results around the cutoffs of the serology assay, nor by high natural turnover of HPV antibody responses. Furthermore, although we confirmed an association of recent sexual intercourse with HPV seropositivity $[6,9,26,27]$, HAART initiation did not appear to increase risky sexual behavior $(46.1 \%$ declaring occasional partners at HAART initiation versus

Table 3. Factors associated with seroconversion ${ }^{a}$ after 24 months among patients human papillomavirus-L1-seronegative at HAART initiation.

\begin{tabular}{|c|c|c|c|c|c|c|}
\hline & \multicolumn{3}{|c|}{ HPV16-L1 } & \multicolumn{3}{|c|}{ Any HR-HPV-L1 ${ }^{\mathrm{b}}$} \\
\hline & $n(\%)$ & OR $(95 \% \mathrm{Cl})$ & $P$ trend & $n(\%)$ & OR $(95 \% \mathrm{Cl})$ & $P$ trend \\
\hline \multicolumn{7}{|l|}{ Age (years) } \\
\hline$\geq 45$ & 15/53 (28.3) & 1 & & 29/78 (37.2) & 1 & \\
\hline $35-44$ & 21/66 (31.8) & $1.16(0.53-2.55)$ & & $45 / 100(45.0)$ & $1.38(0.75-2.53)$ & \\
\hline$<35$ & 19/70 (27.1) & $0.94(0.43-2.09)$ & 0.85 & $41 / 95(43.2)$ & $1.28(0.70-2.37)$ & 0.46 \\
\hline \multicolumn{7}{|l|}{ Tobacco } \\
\hline Ever & 27/113 (23.9) & 1 & & 58/157 (36.9) & 1 & \\
\hline Never & $27 / 75(36.0)$ & $1.79(0.95-3.40)$ & - & $54 / 112(48.2)$ & $1.59(0.97-2.60)$ & - \\
\hline \multicolumn{7}{|l|}{ History of AIDS } \\
\hline No & $41 / 149(27.5)$ & 1 & & $87 / 217(40.1)$ & 1 & \\
\hline Yes & 14/41 (34.2) & $1.24(0.75-2.04)$ & - & 28/56 (50.0) & $1.49(0.83-2.70)$ & - \\
\hline \multicolumn{7}{|c|}{ HIV viral load (copies/ml) } \\
\hline$<10000$ & $6 / 25(24.0)$ & 1 & & $11 / 36(30.6)$ & 1 & \\
\hline $10000-99999$ & 23/71 (32.4) & $1.52(0.53-4.31)$ & & 46/96 (47.9) & $2.09(0.93-4.72)$ & \\
\hline $100000-499999$ & 15/61 (24.6) & $1.03(0.35-3.06)$ & & $33 / 88(37.5)$ & $1.36(0.59-3.13)$ & \\
\hline$\geq 500000$ & 9/26 (34.6) & $1.68(0.49-5.69)$ & 0.78 & $22 / 45(48.9)$ & $2.17(0.87-5.45)$ & 0.42 \\
\hline \multicolumn{7}{|c|}{$\mathrm{CD}^{+}{ }^{+}$cell count $($cells $/ \mu \mathrm{l})$} \\
\hline$\geq 350$ & $7 / 46(15.2)$ & 1 & & 19/65 (29.2) & 1 & \\
\hline $200-350$ & $13 / 47(27.7)$ & $2.13(0.76-5.95)$ & & $26 / 70(37.1)$ & $1.43(0.70-2.94)$ & \\
\hline $50-199$ & $17 / 60(28.3)$ & $2.20(0.83-5.88)$ & & $41 / 89(46.1)$ & $2.07(1.05-4.07)$ & \\
\hline$<50$ & 18/37 (48.7) & $5.28(1.88-14.8)$ & $<0.01$ & $29 / 49(59.2)$ & $3.51(1.61-7.67)$ & $<0.01$ \\
\hline \multicolumn{7}{|c|}{ CD8 ${ }^{+}$cell count $($cells $/ \mu \mathrm{l})$} \\
\hline$\geq 1000$ & $14 / 54(25.9)$ & 1 & & $36 / 85$ (42.4) & 1 & \\
\hline $750-999$ & $16 / 44(36.4)$ & $1.63(0.69-3.88)$ & & $28 / 58(48.3)$ & $1.27(0.65-2.49)$ & \\
\hline $500-749$ & $10 / 45(22.2)$ & $0.82(0.32-2.07)$ & & $22 / 64(34.4)$ & $0.71(0.36-1.40)$ & \\
\hline$<500$ & 15/47 (31.9) & $1.34(0.56-3.18)$ & 0.85 & 29/66 (43.9) & $1.07(0.56-2.04)$ & 0.77 \\
\hline \multicolumn{7}{|l|}{$\mathrm{CD}^{+} / \mathrm{CD}^{+}$ratio } \\
\hline$\geq 0.5$ & $4 / 34(11.8)$ & 1 & & 12/45 (26.7) & 1 & \\
\hline $0.25-0.49$ & 13/52 (25.0) & $2.50(0.74-8.45)$ & & $31 / 79(39.2)$ & $1.78(0.80-3.95)$ & \\
\hline $0.10-0.24$ & $16 / 55(29.1)$ & $3.08(0.93-10.16)$ & & $37 / 84(44.1)$ & $2.16(0.98-4.76)$ & \\
\hline$<0.10$ & $21 / 45(46.7)$ & $6.56(1.98-21.71)$ & $<0.01$ & 34/61 (55.7) & $3.46(1.51-7.96)$ & $<0.01$ \\
\hline
\end{tabular}

$\mathrm{Cl}$, confidence interval; HPV, human papillomavirus; $\mathrm{HR}$, high risk; OR, odds ratio.

${ }^{a}$ Seroconversion = seroconversion of at least one HPV type.

${ }^{\mathrm{b}}$ For any HPV-L1: seronegative = seronegative for at least one HPV type among HPV16, 18, 31, 33, 35, 45, 52 and 58. 
(a)

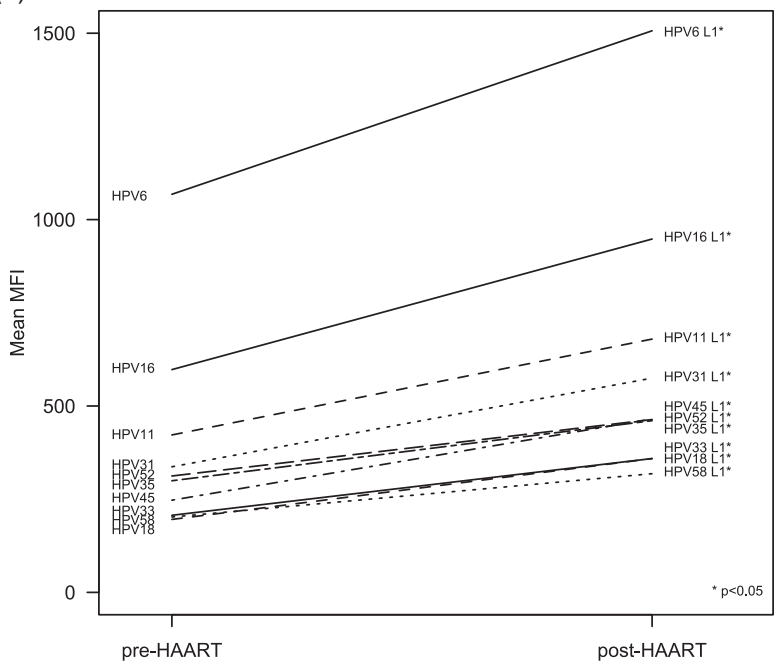

(b)

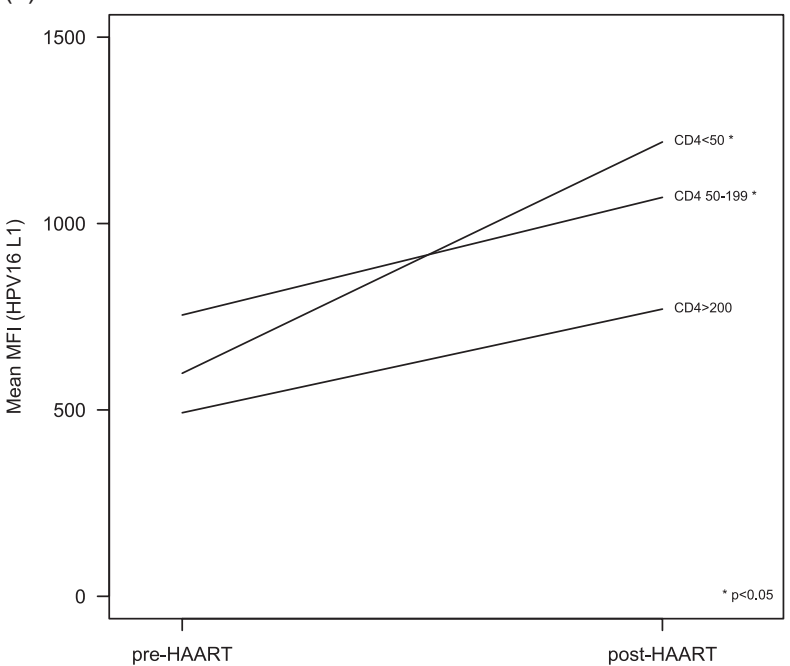

Fig. 1. Mean change in human papillomavirus-L1 antibody response stratified by human papillomavirus type (a) and in human papillomavirus 16-L1 by $\mathrm{CD}^{+}$cell count (b).

$38.4 \%$ at $24-$ month follow-up; data not shown) and hence should also not explain high seroconversion rates. The fact that seroconversion and MFI increases were associated with lower $\mathrm{CD} 4^{+}$cell count and/or $\mathrm{CD}^{+}$/ $\mathrm{CD}^{+}$ratio pre-HAART would suggest that increases in measurable HPV antibodies are principally due to immune reconstitution, rather than exposure to new HPV infections.

In contrast to the effect of low $\mathrm{CD} 4^{+}$cell count on seroconversion and increases in $\mathrm{L} 1$ antibody titers, $\mathrm{CD} 4^{+}$ cell counts were not associated with cross-sectional seroprevalence. This corroborates lack of association of $\mathrm{CD}^{+}{ }^{+}$cell counts with HPV seroprevalence in other HIV-positive MSM [6,7,9] and HIV-positive women [28] and suggests that HAART-related increases in detectable HPV immune responses are not mediated solely via $\mathrm{CD}^{+}{ }^{+}$cell counts. Indeed, we have described a similar phenomenon for Kaposi's sarcoma-associated herpesvirus antibodies in these samples [18].

High type-specific seroprevalences observed in the SHCS are consistent with those reported in other HIV-positive MSM [6,7,9,27], albeit with different serological assays. Based on the same assay and cutoff definition, HPV6 $(53 \%)$ and $11(46 \%)$ seroprevalence in the SHCS was similar to that reported in $245 \mathrm{HIV}$-positive MSM in
Australia (53 and 48\%) [8]. HPV6 and 11 seroincidence, on the other hand, was much higher in the current study (12 and 11 per 100 person-years, calculated using comparable criteria, versus 2.4 and 1.5 per 100 personyears) [8], supporting the theory that HAART initiation is a moment particularly disposed to HPV seroconversion.

HPV-L1 seroprevalence is higher in HIV-positive than HIV-negative MSM [6,27]. This is expected to be related to their higher prevalence of anal HPV infection [1,29], known to be an important determinant of seropositivity in MSM $[9,29]$. Our data, however, confirm that anal HPV exposure is not sufficient for seroconversion in HIVpositive MSM and could explain why anal HPV infection was a significant determinant of HPV seroconversion in HIV-negative, but not HIV-positive, MSM [6] in a crosssectional comparison that did not take HAART into account.

HPV-L1 antibodies acquired through natural infection have been shown to provide modest protection against subsequent HPV infection in female patients, but not in men [30]. This question requires data from large prospective studies with multiple visits, because detectable L1 antibodies are also a marker of exposure and are positively associated with HPV-related cancer $[10,11,13-$ 16]. Indeed, in the present study, all anal cancers occurred

Table 4. Anal cancer incidence according to human papillomavirus 16-L1 and E6 serology status post-HAART.

\begin{tabular}{lcccccc}
\hline & $n$ & Person-years & Anal cancers & Incidence rate $(/ 100000)$ & Incidence rate ratio \\
\hline HPV16-L1 & Negative & 146 & 1685 & 0 & 0 & 1 \\
\multirow{2}{*}{ HPV16-E6 } & Positive & 133 & 1528 & 3 & $196(63-609)$ & $\infty(0.5-\infty)$ \\
& Negative & 276 & 3187 & 2 & $63(16-254)$ & 1 \\
& Positive & 3 & 25 & 1 & $3956(557-28086)$ & $63.1(1.1-1211)$ \\
\hline
\end{tabular}

HPV, human papillomavirus. 
in MSM who were HPV16-L1-seropositive postHAART.

HPV vaccination results in far greater seroconversion rates and antibody titers than natural HPV infection. Interestingly, in two studies of quadrivalent HPV vaccine of immunogenicity among HIV-infected men [31] and women [32], no relationships between HPV antibody concentrations and $\mathrm{CD}^{+}{ }^{+}$cell counts were observed, but higher antibody concentrations were reported in HAART users. This suggests that the $\mathrm{CD} 4^{+}$-independent effect of HAART on immune response that we have described in the SHCS for natural HPV infection may also play a role in vaccine-induced HPV antibody response, even if the clinical significance of lower L1 antibody concentrations remains unknown because there is no established threshold correlating with protection.

HPV16-E6 antibodies have already been shown to be specific, but insensitive, markers of cervical [12] and anal [10] cancer in the SHCS, but the present study is the first to provide prospective data on the meaning of HPV16-E6 antibodies for future risk of $\mathrm{HPV}$-related cancer in HIVpositive populations. In our study of HIV-positive MSM, only one patient $(0.4 \%)$ was HPV16-E6-seropositive at HAART initiation and remained cancer-free during his entire 15-year follow-up. Two more HPV16-E6-seropositive cases were revealed post-HAART, however, of which one developed anal cancer 11 years later, so that HPV16-E6 positivity post-HAART was associated with a 63-fold significant increase in anal cancer incidence, albeit with very wide $95 \%$ CIs. Two out of the three anal cancers were E6-seronegative, however, confirming observations in the general (30\% of anal cancers E6seropositive [15]) and HIV-positive (22\% [10]) population of a low sensitivity of HPV16-E6 antibody for predicting anal cancer.

The principal novelty of our study design is represented by samples selected at a 2 -year interval pre-HAART and post-HAART in a large and well characterized group of HIV-positive MSM. Indeed, this set of samples has been previously used to describe the effect of HAART on Kaposi's sarcoma-associated herpesvirus viremia and antibodies [18]. In addition, however, 15-year followup, during which time the SHCS has been regularly linked with cancer registries [3,20], allowed an ad-hoc cohort analysis of HPV-related cancer risk. Despite small absolute numbers, high anal cancer incidence rates (132 per 100000 person-years) were comparable with other estimates in HIV-positive MSM in the HAART era (131 per 100000 person-years [4]) and enabled us to identify significant serological determinants (HPV16-E6) of anal cancer risk. Of note, the absence of other HPVrelated cancer diagnoses is consistent with the estimation that anal cancer accounts for 85\% of HPV-related cancers in HIV-infected populations [33]. Other study limitations include the lack of control group of HIV + MSM against which to compare 2-year HPV seroconversion (e.g. naive or long-term HAART users) and the unavailability of a measure of HPV DNA, particularly from the anus, that prevented us from distinguishing seropositivity related to past or present infections. Although we had L1 serological assays for only eight of the $12 \mathrm{HPV}$ types that have been designated as high-risk based on their carcinogenicity at the cervix, and only HPV16-E6, HPV16 is the only HPV type established as a cause of anal cancer [34], and is by far the predominantly detected type in large cases series of anal cancer [2,35], including those diagnosed among HIV-positive persons [36,37]. In addition, there is evidence for some cross-reactivity of HPV E6, but not L1, assay antigens, for antibodies of closely phylogenetically related types [13].

With respect to estimating the fraction of HIV-positive MSM who may profit from primary anal cancer prevention by prophylactic HPV vaccination, we show that seropositivity against HPV16 and other high-risk HPV types is already very high in HAART-naive HIVinfected MSM and that HAART reveals previously undetectable antibody responses in an additional fraction. This adds to evidence that not all anal HPV infections result in detectable immune responses [6,7], so that a definition of HPV seronegativity overestimates the truly HPV-naive population. With respect to secondary anal cancer prevention, our results suggest that HPV16-E6 antibodies might have some predictive value for risk stratification of HIV-positive MSM, at least among those commencing HAART. However, these findings remain preliminary, and there remains little consensus about the utility and/or the appropriate algorithm for further diagnostic work-up and treatment.

\section{Acknowledgements}

G.M.C. and S.F. conceived the study. J.-D.C. performed data analysis and drafted the manuscript. T.W. performed the HPV serology testing. A.U.S. was responsible for management of the clinical database of the Swiss HIV Cohort Study (SHCS) and liaison with the SHCS centers and Scientific Board. M.E., M.C., H.H.H., C.H., A.C., P.S., E.B. and H.F.G. represent the individual Swiss cohort centers responsible for acquiring the clinical and epidemiological follow-up data. All authors read and gave feedback to the final version of the manuscript.

The study was performed within the framework of the Swiss HIV Cohort Study (SHCS-project 495), supported by the Swiss National Science Foundation (grant 148522); and OncoSuisse (ICP OCS 01355-03-2003, KFS-02478-08-2009). The authors thank Dr Kristina Michael for support in the serological analyses.

The members of the Swiss HIV Cohort Study are Aubert V, Battegay M, Bernasconi E, Böni J, Braun DL, Bucher 
HC, Calmy A, Cavassini M, Ciuffi A, Dollenmaier G, Egger M, Elzi L, Fehr J, Fellay J, Furrer H (Chairman of the Clinical and Laboratory Committee), Fux CA, Günthard HF (President of the SHCS), Haerry D (Deputy of the 'Positive Council'), Hasse B, Hirsch HH, Hoffmann M, Hösli I, Kahlert C, Kaiser L, Keiser O, Klimkait T, Kouyos RD, Kovari H, Ledergerber B, Martinetti G, Martinez de Tejada B, Marzolini C, Metzner KJ, Müller N, Nicca D, Pantaleo G, Paioni P, Rauch A (Chairman of the Scientific Board), Rudin C (Chairman of the Mother \& Child Substudy), Scherrer AU (Head of Data Centre), Schmid P, Speck R, Stöckle M, Tarr P, Trkola A, Vernazza P, Wandeler G, Weber R, Yerly S.

\section{Conflicts of interest}

There are no conflicts of interest.

\section{References}

1. Machalek DA, Poynten M, Jin F, Fairley CK, Farnsworth $A$ Garland SM, et al. Anal human papillomavirus infection and associated neoplastic lesions in men who have sex with men: a systematic review and meta-analysis. Lancet Oncol 2012; 13:487-500.

2. de Vuyst $\mathrm{H}$, Clifford GM, Nascimento MC, Madeleine MM Franceschi S. Prevalence and type distribution of human papillomavirus in carcinoma and intraepithelial neoplasia of the vulva, vagina and anus: a meta-analysis. Int / Cancer 2009; 124:1626-1636.

3. Franceschi S, Lise $M$, Clifford GM, Rickenbach $M$, Levi $F$, Maspoli $M$, et al. Changing patterns of cancer incidence in the early- and late-HAART periods: the Swiss HIV Cohort Study. Br J Cancer 2010; 103:416-422.

4. Silverberg MJ, Lau B, Justice AC, Engels E, Gill MJ, Goedert JJ, et al. Risk of anal cancer in HIV-infected and HIV-uninfected individuals in North America. Clin Infect Dis 2012; 54: 1026-1034.

5. Giuliano AR, Viscidi R, Torres BN, Ingles DJ, Sudenga SL, Villa $\mathrm{LL}$, et al. Seroconversion following anal and genital HPV infection in men: The HIM Study. Papillomavirus Res 2015; 1:109-115.

6. Mooij SH, van der Klis FR, van der Sande MA, Schepp RM, Speksnijder AG, Bogaards JA, et al. Seroepidemiology of highrisk HPV in HIV-negative and HIV-infected MSM: the H2M study. Cancer Epidemiol Biomarkers Prev 2013; 22: 1698-1708.

7. Hagensee ME, Kiviat N, Critchlow CW, Hawes SE, Kuypers J, Holte $S$, et al. Seroprevalence of human papillomavirus types 6 and 16 capsid antibodies in homosexual men. I Infect Dis 1997; 176:625-631.

8. Poynten IM, Jin F, Templeton DJ, Prestage GP, Donovan B, Pawlita $M$, et al. Prevalence, incidence, and risk factors for human papillomavirus 16 seropositivity in Australian homosexual men. Sex Transm Dis 2012; 39:726-732.

9. Sharma R, Efird JT, Chein A, Holly EA, Krajden M, Berry JM, et al. Prevalence and risk factors for neutralizing antibodies to human papillomavirus types 16 and 18 in HIV-positive men who have sex with men. J Acquir Immune Defic Syndr 2013; 64: 479-487.

10. Bertisch B, Franceschi S, Lise M, Vernazza P, Keiser O, SchoniAffolter $F$, et al. Risk factors for anal cancer in persons infected with HIV: a nested case-control study in the Swiss HIV Cohort Study. Am / Epidemiol 2013; 178:877-884.

11. Castellsague X, Pawlita M, Roura E, Margall N, Waterboer T, Bosch FX, et al. Prospective seroepidemiologic study on the role of Human Papillomavirus and other infections in cervical carcinogenesis: evidence from the EPIC cohort. Int / Cancer 2014; 135:440-452.
12. Clifford GM, Franceschi S, Keiser O, Schoni-Affolter F, Lise M, Dehler $S$, et al. Immunodeficiency and the risk of cervical intraepithelial neoplasia $2 / 3$ and cervical cancer: a nested case-control study in the Swiss HIV cohort study. Int I Cancer 2016; 138:1732-1740.

13. Combes JD, Pawlita M, Waterboer T, Hammouda D, Rajkumar $\mathrm{T}$, Vanhems $\mathrm{P}$, et al. Antibodies against high-risk human papillomavirus proteins as markers for invasive cervical cancer. Int J Cancer 2014; 135:2453-2461.

14. D'Souza G, Kreimer AR, Viscidi R, Pawlita M, Fakhry C, Koch WM, et al. Case-control study of human papillomavirus and oropharyngeal cancer. N Eng/ / Med 2007; 356:1944-1956.

15. Kreimer AR, Brennan P, Lang Kuhs KA, Waterboer T, Clifford G Franceschi $\mathrm{S}$, et al. Human papillomavirus antibodies and future risk of anogenital cancer: a nested case-control study in the European prospective investigation into cancer and nutrition study. J Clin Oncol 2015; 33:877-884.

16. Kreimer AR, Pierce Campbell CM, Lin HY, Fulp W, Papenfuss $M R$, Abrahamsen $M$, et al. Incidence and clearance of oral human papillomavirus infection in men: the HIM cohort study. Lancet 2013; 382:877-887.

17. Waterboer T, Sehr P, Michael KM, Franceschi S, Nieland JD, Joos TO, et al. Multiplex human papillomavirus serology based on in situ-purified glutathione s-transferase fusion proteins. Clin Chem 2005; 51:1845-1853.

18. Sullivan SG, Hirsch HH, Franceschi S, Steffen I, Amari EB Mueller NJ, et al. Kaposi sarcoma herpes virus antibody response and viremia following highly active antiretroviral therapy in the Swiss HIV Cohort study. AIDS 2010; 24:2245-2252.

19. Schoeni-Affolter F, Ledergerber B, Rickenbach $M$, Rudin C, Gunthard HF, Telenti A, et al. Cohort profile: the Swiss HIV Cohort study. Int J Epidemiol 2010; 39:1179-1189.

20. Clifford GM, Polesel J, Rickenbach M, Dal ML, Keiser O, Kofler A, et al. Cancer risk in the Swiss HIV Cohort Study: associations with immunodeficiency, smoking, and highly active antiretroviral therapy. I Natl Cancer Inst 2005; 97:425-432.

21. Sehr P, Zumbach K, Pawlita M. A generic capture ELISA for recombinant proteins fused to glutathione S-transferase: validation for HPV serology. I Immunol Methods 2001; 253 (12):153-162.

22. Sehr P, Muller M, Hopfl R, Widschwendter A, Pawlita M. HPV antibody detection by ELISA with capsid protein L1 fused to glutathione $\boldsymbol{S}$-transferase. I Virol Methods 2002; 106:61-70.

23. Waterboer T, Sehr P, Pawlita M. Suppression of nonspecific binding in serological Luminex assays. I Immunol Methods 2006; 309 (1-2):200-204.

24. Clifford GM, Shin HR, Oh JK, Waterboer T, Ju YH, Vaccarella S, et al. Serologic response to oncogenic human papillomavirus types in male and female university students in Busan, South Korea. Cancer Epidemiol Biomarkers Prev 2007; 16:1874-1879.

25. Lang Kuhs KA, Pawlita M, Gibson SP, Schmitt NC, Trivedi S, Argiris $\mathrm{A}$, et al. Characterization of human papillomavirus antibodies in individuals with head and neck cancer. Cancer Epidemiol 2016; 42:46-52.

26. Poynten IM, Waterboer T, Jin F, Templeton DJ, Prestage G, Donovan $B$, et al. Human papillomavirus types 6 and $\mathbf{1 1}$ seropositivity: risk factors and association with ano-genital warts among homosexual men. J Infect 2013; 66:503-511.

27. Alberts CJ, van Rooijen MS, Prins M, Pawlita M, SvdL MF, Waterboer T. HIV is an important risk factor for human papillomavirus types 16 and 18 seropositivity among sexually active men who have sex with men. Sex Transm Dis 2015; 42:129-134.

28. Viscidi RP, Ahdieh-Grant L, Schneider MF, Clayman B, Massad LS, Anastos KM, et al. Serum immunoglobulin A response to human papillomavirus type 16 virus-like particles in human immunodeficiency virus (HIV)-positive and high-risk HIVnegative women. J Infect Dis 2003; 188:1834-1844.

29. van Rijn VM, Mooij SH, Mollers M, Snijders PJ, Speksnijder AG, King AJ, et al. Anal, penile, and oral high-risk HPV infections and HPV seropositivity in HIV-positive and HIVnegative men who have sex with men. PLOS One 2014 9:e92208.

30. Beachler DC, Jenkins G, Safaeian M, Kreimer AR, Wentzensen $\mathrm{N}$. Natural acquired immunity against subsequent genital Human Papillomavirus infection: a systematic review and metaanalysis. J Infect Dis 2016; 213:1444-1454. 
31. Wilkin T, Lee JY, Lensing SY, Stier EA, Goldstone SE, Berry JM, et al. Safety and immunogenicity of the quadrivalent human papillomavirus vaccine in HIV-1-infected men. I Infect Dis 2010; 202:1246-1253.

32. Kahn JA, Xu J, Kapogiannis BG, Rudy B, Gonin R, Liu N, et al. Immunogenicity and safety of the human papillomavirus 6, 11, 16, 18 vaccine in HIV-infected young women. Clin Infect Dis 2013; 57:735-744.

33. de Martel C, Shiels MS, Franceschi S, Simard EP, Vignat J, Hall $\mathrm{HI}$, et al. Cancers attributable to infections among adults with HIV in the United States. AIDS 2015; 29:2173-2181.

34. IARC. Biological agents. IARC Monogr Eval Carcinog Risks Hum 2012; 100B:1-475.
35. Alemany L, Saunier M, Alvarado-Cabrero I, Quiros B, Salmeron J, Shin HR, et al. Human papillomavirus DNA prevalence and type distribution in anal carcinomas worldwide. Int / Cancer 2015; 136:98-107.

36. Abramowitz $L$, Jacquard AC, Jaroud F, Haesebaert J, Siproudhis $L$, Pradat $P$, et al. Human papillomavirus genotype distribution in anal cancer in France: the EDiTH V study. Int J Cancer 2011; 129:433-439.

37. Hillman RJ, Garland SM, Gunathilake MP, Stevens M, Kumaradevan N, Lemech $C$, et al. Human papillomavirus (HPV) genotypes in an Australian sample of anal cancers. Int / Cancer 2014; 135:996-1001. 